\title{
Application of Passive Cooling Techniques in Residential Buildings: A Case Study of Northern Nigeria
}

\author{
Muktar Inusa*, Asst. Prof. Dr. Halil Zafer Alibaba** \\ *(Department of Architecture, Eastern Mediterranean University, Gazimağusa, North Cyprus) \\ ** (Department of Architecture, Eastern Mediterranean University, Gazimağusa, North Cyprus)
}

\begin{abstract}
In this paper a critical analysis of how to passively cool residential buildings in Northern Nigeria was made.in particular passive design and some passive cooling strategies were analyzed. The physical properties permitting to achieve these benefits is presented as well as ways by which they can be applied. Energy in Nigeria has been a major challenging issue as the government has been struggling to increase the national grid. This paper identifies passive design strategies that can be adopted in this climatic region to minimize the use of energy for cooling, greatly boost thermal comfort and embroider passive architecture. It is most important to achieve thermal comfort through natural means or energy efficient means. The paper discusses methods by which the cooling load of buildings can be reduced tremendously and to maximize the use of natural ways to achieve thermal comfort in buildings, it also shows the ways these passive design and cooling strategies can be adopted. The paper concludes that the application of these techniques will reduce energy demand and provide a more comfortable living environment and low carbon emitting buildings that are environmentally conscious and energy efficient.
\end{abstract}

Keywords: Thermal comfort, Energy, Passive cooling, Sustainable, Northern Nigeria, Natural ventilation, cooling load

\section{INTRODUCTION}

Passive cooling has a holistic approach. This is because it integrates the buildings design, material selection and techniques of construction to reduce the heating of the building or to increase the cooling as the case may be, taking into cognizance the climatology of the area, relative humidity, wind direction and solar radiation to create conservative buildings.

It covers all natural processes and techniques for cooling buildings. It is cooling without any form of energy input, other than renewable energy sources. Passive cooling techniques are also closely linked to the thermal comfort of the occupants. It is also possible to increase the effectiveness of passive cooling with mechanically assisted heat transfer techniques, which enhance the natural cooling processes [1].

Energy consumption is maintained at very low level, but the efficiency of the systems and their applicability is greatly improved. It maintains a delicate balance between the human need to improve lifestyles and feeling of well-being on one hand, and preserving natural resources and ecosystems, on which we and future generations depend [2].

\section{DESCRIPTION OF THE STUDY} AREA

Between the vast arid expanse of the Sahara and the dense tropical rain forest lies the province that constitutes Northern Nigeria. The climate is characterized by high temperatures and low humidity in the dry season. The diurnal temperature varies from an average daily maximu $\mathrm{m}$ of $31.6^{\circ} \mathrm{C}$ to a daily minimum of $13.1^{\circ} \mathrm{C}$. The mean relative humidity is highest in August (66.5\%) and lowest in February $(16.5 \%)$. The mean annual rainfall ranges between $800-900 \mathrm{~mm}$ per annum and only $700 \mathrm{~mm}$ per annum in the extreme north. The dry season occurs between September and May, while the rainy season is between May and September. The hottest month in this region is April with $40.5^{\circ} \mathrm{C}$, while the coldest months are December and January, with $6.11^{\circ} \mathrm{C}$ and $7.22^{\circ} \mathrm{C}$ respectively [3].

\section{PROBLEM STATEMENT}

The modern construction and design techniques of building homes has been widely accepted in the region but modern architecture in Nigeria has not been clearly defined. Buildings became more and more aesthetically pleasing but not energy efficient. This entails the use of excessive energy in cooling. The adaptation was not a problem because it was an improvement in the way homes were built, but the problem here is the disregard for energy efficiency and relying so much on the national grid. That is why we must apply some passive techniques to see how the principles can be applied to provide energy efficient buildings. Buildings today Nigeria are designed with little or no consideration for energy efficiency. Houses in Nigeria were built using sand Crete blocks with 
cement render and roofed with aluminum roof covering. However, insulation materials were not installed in these houses. Most of the building façades are exposed to solar radiations that absorb heat during the day. This heat is transferred to the inner spaces, thereby creating thermal discomfort for the building occupants. To make the situation worse, these houses have poor ventilation and air circulation, As a result, the heat inside the house is normally trapped by room partitions and doors that increase the internal temperature Excessive heating can be minimized, then the problem of providing sufficient cooling will be half-solved. Externally generated cooling loads are due to sunshine through windows or on the outside of walls or roofs, hot air entering the building or heat conducted from hot outside air to the inside [4]: [5].

\section{OBJECTIVE OF STUDY}

The objective is to achieve thermal comfort by the application of some passive cooling techniques to create energy efficient homes. And to determine the practicability of these techniques, whether or not they can be adopted, and if they can perfom in a manner that the mechanical cooling systems be replaced so as to reduce energy demand from the national grid.

\section{METHODOLOGY}

The following techniques were adopted to determine the proper application of passive cooling for hot-humid climate buildings in Northern Nigeria in order to solve the energy problems and provide thermal co mfort.

When Passive cooling techniques are used for cooling and ventilation of buildings. The first concern is however how to avoid cooling loads and then how to cool down the building follows. We will consider two major approaches, these are Reduction of Heat Gain through Passive Design and Dissipation of Heat Using Passive Cooling Strategies.

\subsection{Reduction Of Heat Gain Through Passive Design}

It is necessary to cool down the temperature in a building, but it is more important to prevent the building from gaining it unnecessarily. Passive design is the process of designing a building while ensuring that it gains minimum heat and ensures that it requires little or no mechanical energy to achieve thermal comfort. This approach to passive cooling takes advantage of natural air flow to provide comfort in a building. It improves comfort, drastically reduces energy bills and it also prevents the release of toxic gases into the atmosphere [6].

This method ensures that the building envelope controls heat gain and heat loss. This concept works as a two way system to provide thermal comfort at the two extreme weather situations as it can provide heat storage when needed and dissipation as the case may be. These design techniques vary according to the different climatic situations. To explain this method further, below are the guiding principles.

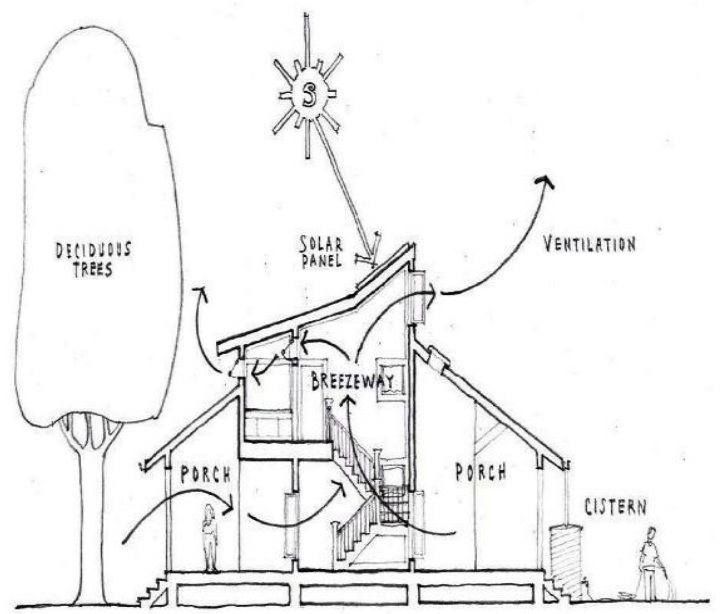

Figure 1: How pas sive cooling works (Source: www.greenbuilder.com).

\subsubsection{Bioclimatic analysis.}

The climate of an area where a building is to be situated plays a major role in the design and specification of materials used. This is because climate is the atmospheric condition of the place over a long period of time. It is as a result of the influence of the topography, soil structure, temperature, precipitation and wind. The climatic condition of a geographic location could differ due to human activity, ambient temperature, relative humidity, wind speed and solar radiation. These factors must be digressed and put in harmony with the proposed design.

\subsubsection{Building orientation and sol ar geome try.}

A building well oriented on site could deliver a compelling betterment to the comfort of its occupants. A buildings orientation in hot climates must be from a solar point of view, because the maximum daytime temperature goes up to 40 degrees centigrade. It should be such that non habitat rooms be used as barriers from the sun, they are therefore placed at the facades that receive the most solar heat. The longer facades should face the north and south, there receiving a lower solar heat, which makes those sides most suitable for locating living rooms. The kitchen on the other hand should be placed at the leeward side of the building to avoid circulation of hot air [7]. 


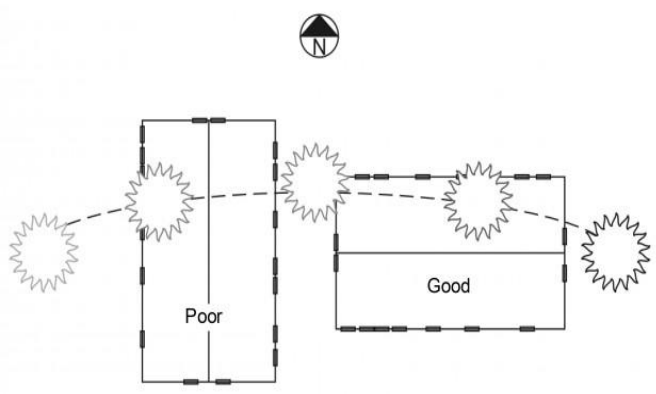

Figure 2: Sun path (Source: UF/IFAS Program)

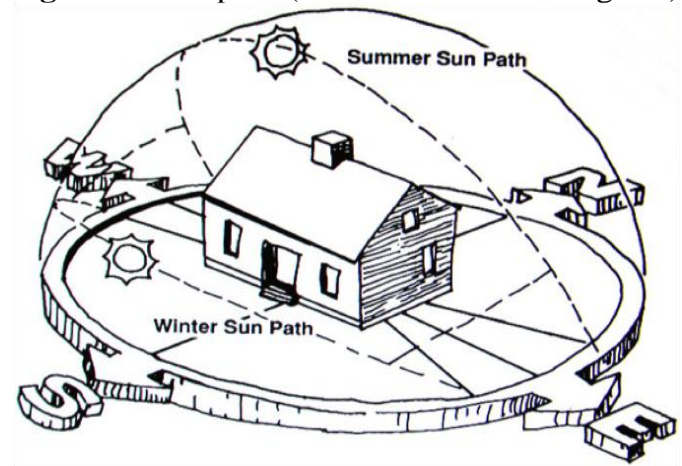

Figure 3: Solar path for winter and summer

(Source: www.greentechconstruction.com)

\subsubsection{Building Insulation.}

It is essential to make the building envelope resistant to external climatic factors especially the unwanted ones and hence the need and importance of insulation. The building envelope comprises of walls, floors and roofs, all these elements in a building can be insulated from either heat loss or gain as the case may be. The type and quality of an insulation material is strongly determined by the climate as different insulation materials offer different qualities, PCM integrated facades have the ability to store heat during the day and discharge it during the night through radiation [5].

In hot climates, roof could be made reflective a Reflective Foil Laminate (RFL). In other cases sarking could be used by placing boards underneath the roofing sheet. The use of dense materials like concrete, bricks and other similar materials that absorb, store and release energy to optimize diurnal ext remes should be considered [7].

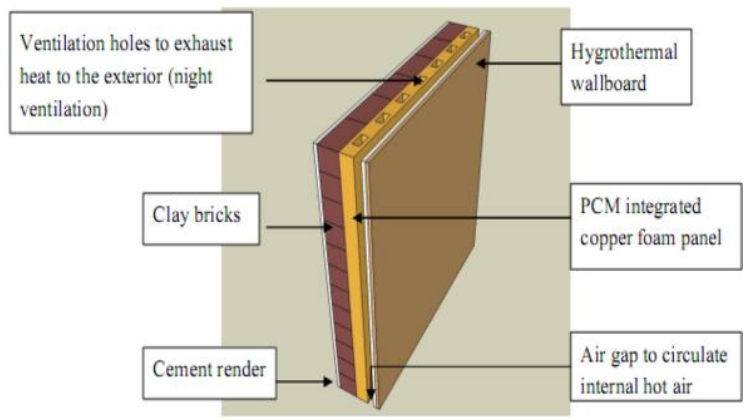

Figure 4: Wall materials installed with copper foam integrated PCM panels Source: [5].

\subsubsection{Glazing.}

Heat loss and heat gain is most accounted for by doors and windows than any other element of the building envelope. The glazing system has to be well designed in such a manner that it reduces glare and improves indoor thermal quality. A well designed glazing system reduces the amount of energy needed to cool down a building which is the main point of this paper. The thermal performance of the glazing must be adequate as well as well as being glare resistant while allowing solar radiation into the building. Some of the glasses could be double or even triple glazing depending on the design specification or building regulations. According to (http www.yourhome.gov.au) $87 \%$ of unwanted heat in summer comes into a building through the windows and doors. Glass is a good thermal conductor and as such, double and triple glazing work to conflict that fact by trapping air or gas that serves as a barrier between indoor and outdoor.
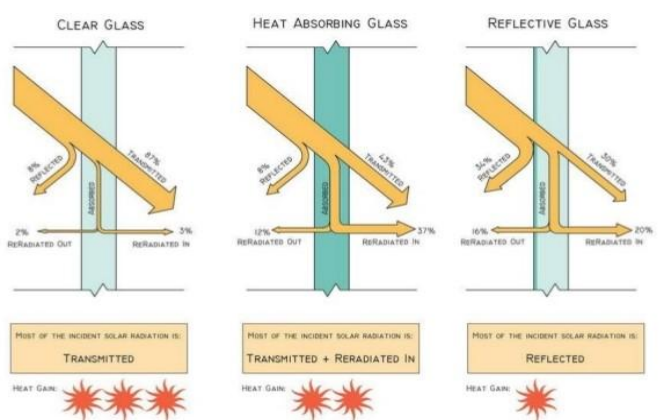

Figure 5: Solar transmission through varying types of glasses. Source [8].

\section{Window Glazing Types}

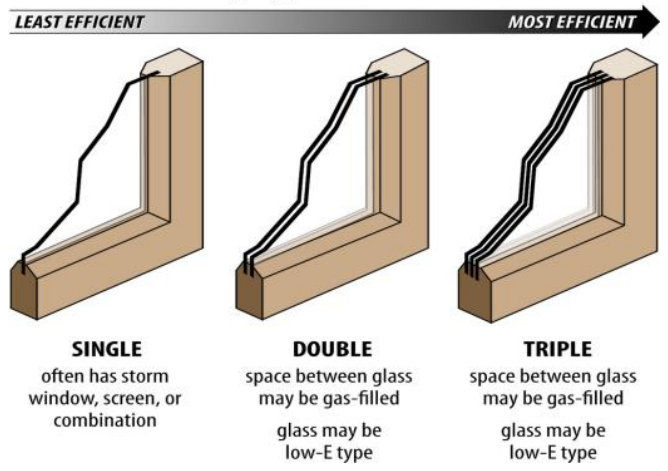

Figure 6: Glazing types (source: www.flickr.com)

\subsubsection{Shading.}

Shading is the fractional or imperforate barrier of sunrays directed to a surface. This varies in position and size depends on the geometric relationship of the sun and the building's façade. An analysis should be carried out to measure the integration between these two elements. A simulation of the daylight performance could be carried out at the design stage to enable the designer 
have a fore knowledge of the daylight assessment of the building. The roof is an integral part of the shading elements as it is the overall cover of the building and its overhangs provides shade around the building therefore protecting the building envelope from unwanted heat [6]. Materials with low thermal capacity should be used near opening so that they quickly cool down after sunset, so as not to return their heat back into the building [9].

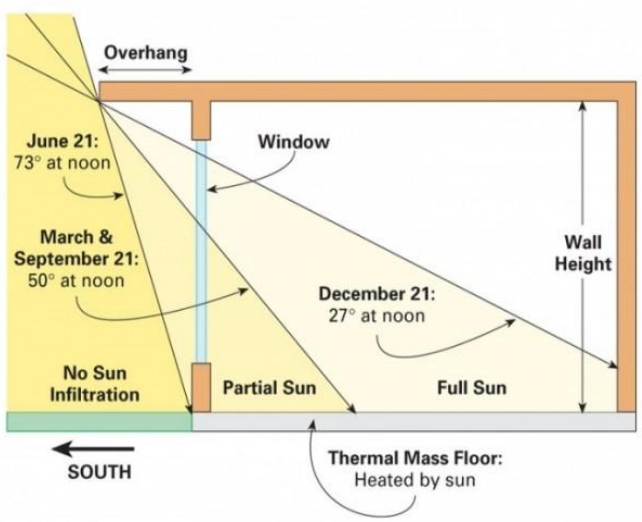

Figure 7: Roof overhang for North latitude (source: www.greenbuildingadvis or.com)

\subsection{Passive Cooling Through Removal Of Excess Heat}

This study concentrates on two types of cooling systems, these are Evaporative cooling and Radiative cooling

\subsubsection{Evaporative Cooling}

This method entails the use natural effect of natural effect of evaporation to cool down the air or to remove heat from the air. This air could be the incoming or exiting air. Heat is absorbed as latent heat necessary to evaporate water, whereby hot air is converted to cool moist air where the heat necessary to evaporate water. The hot air is converted to cool moist air where the heat in the air evaporates the water. The heat absorbed is in cognizance to the quantity or volume of water that is evaporated. As this paper is concentrating on the passive evaporation system, the system is divided into two main categories, these are Passive direct evaporative systems and Passive indirect evaporative systems.

\subsubsection{Passive Direct Evaporative System.}

This can further be sub categorized into two groups, these are the Use of vegetation and the Use of Stark Ventilation (Bernoulli Effect)

\section{- Use of Vegetation}

Trees and other plants evaporate moisture especially during a hot summer day due to their high cooling potential. An average sized deciduous tree can evaporate up to $1460 \mathrm{~kg}$ of water as its corresponding cooling effect is around $240 \mathrm{kwh}$ that is $2320 \mathrm{kj}$ per $\mathrm{kg}$ of evaporated water. This has a potential of reducing energy requirement of air conditioning by between 250 and $650 \mathrm{kWh}$ of electricity per year and in some studies, it was discovered that these trees bring about a temperature reduction of about 2-3 degrees centigrade. Evaporation from wet spaces depends on the velocity of air and the difference between water vapor and air pressure respectively which makes fountains, pools and ponds effective passive cooling elements. Vegetation provides shade for the surrounding ground and reduces its temperature, it also has the ability to absorb intense heat and emit so little, this is due to its low emissivity quality (source: www.greenbuilder.com).

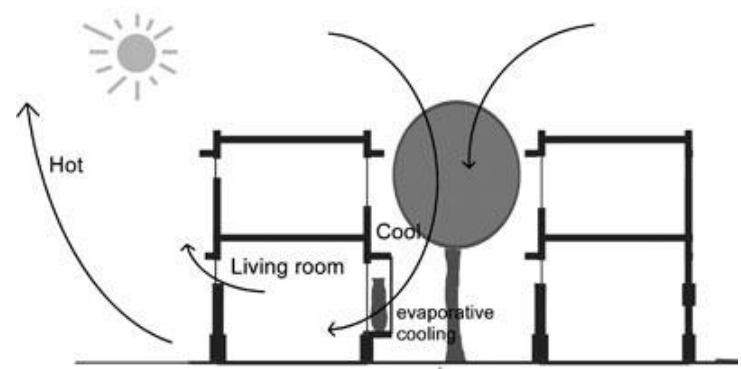

Figure 8: Evaporative cooling (source: D Thorpe 2014)

\section{- Stark Ventilation (Bernoulli effect)}

This is a natural mechanis $\mathrm{m}$ of moving hot air upwards and expelling it into the atmosphere, naturally air with higher temperature tends to move upwards. The application or provision of a stark ventilation system will take advantage this phenomenon. The system uses air pressure differences to pull air through the building. It uses the temperature of the air to move it. In this strategy, the rate of ventilation is proportional to the area of the openings, so therefore openings will be placed at the top and bottom of the building (source: Autodesk.com/sustainability workshop)

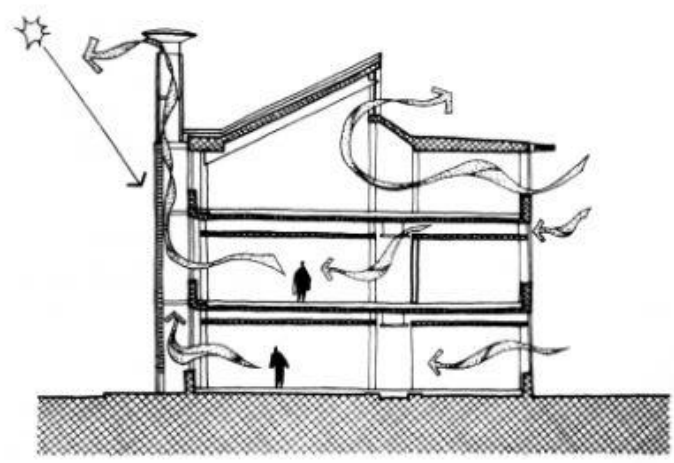

Figure 9: The stack effect, hot air rises due to buoyancy and its low pressure sucks in fresh air from outside (source: Autodesk.com/sustainability workshop). 


\subsubsection{Passive Indirect Evaporation System.}

This includes roof sprinkling system, roof ponds and moving water films.

\section{- Roof sprinkling system}

This is a quite interesting method as most buildings today have flat roofs. The main source of heat or external heat gain is from the roof, and this is because the roof of a building is the most exposed part of a building to the sun. This system is based on evaporation of a water mist layer created by misting spray heads on top of the roof. An appreciable amount of heat is dissipated as the water evaporates.

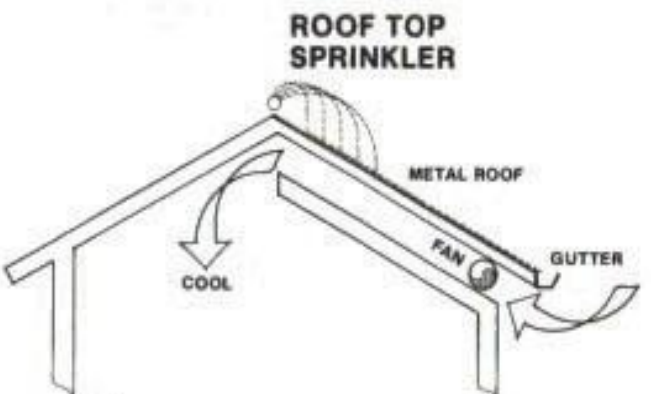

Figure 10: Roof top sprinkler - (source: Arizona Solar Center 2009)

\section{- Roof pond}

This is a much simpler method than the sprinkler system. Water ponds are constructed over flat roofs to avoid excess heating by the sun, the pond is covered or shaded. The water cools the building by conduction. This decreases both indoor air temperature and radiant temperatures with an increase in humidity. This is only applied on water insulated roofs and is recommended for regions with mostly hot climate in other to prevent heat loss in winter.
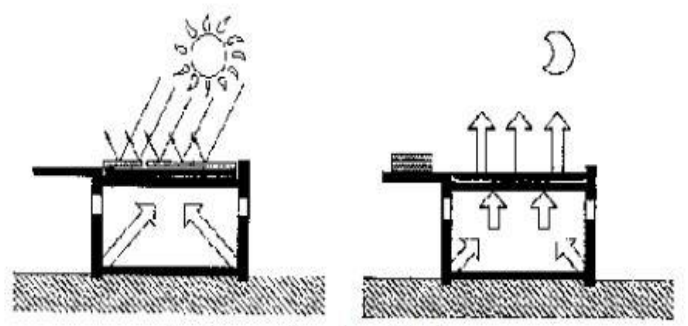

Figure 11: Roof pond during summer [9].

\section{- Moving water films}

These method is based on the circulation of water through films embedded in ceilings and walls whereby the increase in the velocity between air and water surface enhances the evaporation process. The water is stored in the basement and is pumped through these films to cool down the building, this method can also heat the building during winter as the water underground is hot during winter so therefore the reverse happens.

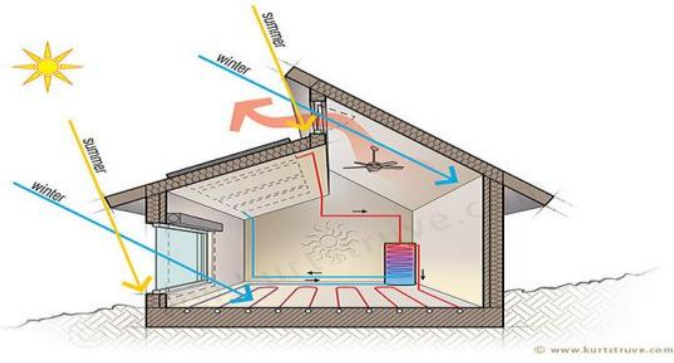

Figure 12: Capillary water moving films in floor and ceiling (Source: www.kurtstruve.com)

\subsubsection{Radiative Cooling}

This has extensively been one of the most energy efficient means of cooling buildings, the principle uses outer space as this infinite energy sink. Radiative cooling is as a result of heat loss by long wave radiation emission from a body with higher temperature to a body with low temperature and plays a role of a heat sink. This occurs due to the low sky temperature especially at night. The difference between sky temperature and ambient temperature is around -10 degrees centigrade during a summer night.

The transmission of energy is caused by the emission of radiation over a spectrum of different wavelengths, a property exhibited by all surfaces and by the significant differences between the temperature of space and that of the objects on earth, this approach to cooling is passive.

Surfaces can be designed to enhance the difference between the net radiated energy, the sky and the surface of the building. This is so that the designer takes advantage of an atmospheric window. This is the period where the atmospheres absorption of heat energy is low (see figure 13). In this case, it is the period between 7.5 and $13 \mu \mathrm{m}$. Radiative cooling has the potential to replace totally the air condition system but in order to achieve that, the surfaces of the building must be designed in such a way that they emit energy until the surface temperature becomes lower than that of the ambient air. [10].

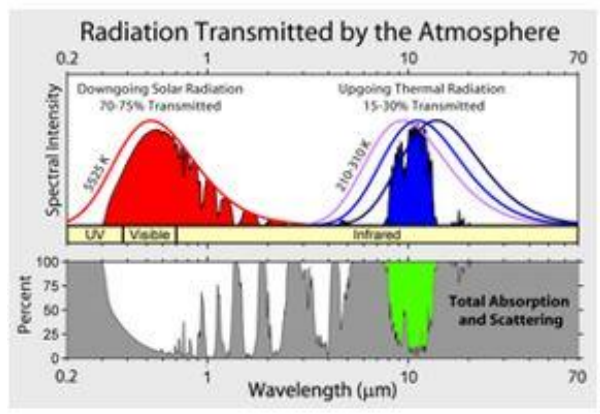

Figure 13.Top: Wavelength and intensity ranges of short-wave and long-wave radiation. Bottom:

Transmittance of light through the atmosphere versus wavelength (source Wikimedia commons). 


\section{FINDINGS AND DISCUSSIONS.}

Based on the study made, it is apparent that the use of air conditioning in the residential buildings can be reduced tremendously to the minimum. We can now build houses that are environmentally responsible and are most comfortable to occupy with very little energy demand. The heat load of the build ings is reduced by the use of the above techniques. The air or breeze that flows around a building can be properly utilized by creating water bodies around the buildings, these could be pons or swimming pools. It is also possible to use timber screen and aluminum screens on the buildings facades, these screens channel the cool breeze into the building to cool down the internal air as the water bodies around the buildings act as swamp coolers. An extensive roof overhang could be created to support the open screens, this might not be visually appealing but it helps cool down the building. A good attic ventilation should be provided by the use of solar attic fan to expel the heat in the roof.

The upper level of the building can be cantilevered so much so that it provides much shade to the lower floor, this is because the spaces occupied during the day mostly are lounging areas and are on the ground floor, and this creates a shaded cool area for the inhabitants to relax [11].

The positioning of functional spaces appropriately can give way to the creation of buffer zones, in this regard, bathrooms, service areas and staircases could be places on sides that are subject to heating at peak hours, these functions serves as buffer zones for other living spaces. Rooms should be positioned in such a way that cross ventilation is achieved. Windows should be positioned in a manner that they align with one another in opposite direction allowing cool air to flow in and out of the building. High level windows are necessary to expel hot air as hot air rises. This can be achieved when the plan is made open and as free as possible.

Materials selection plays an important role as well, materials with good thermal resistance should be selected and colors that absorb heat must be avoided, these colors are and other warm colors. The choice of roofing material should be made in consideration of heat absorption and dissipative qualities, it is most preferable to use cool colored clay roofing tiles or concrete roof because of their thermal resistant qualities. The floors should also be finished with materials that absorb heat and store away from the surface and dissipate the heat when it is needed.

Coniferous trees may be used as shading elements, this is because it has the ability to lose its leaves during the winter to allow winter sun heat the house and the leaves grow back by summer to shade the house.
Radiation cooling strategy was however was adopted to further cool down the building envelope, this occurs when the net emission of electro magnetic waves moves from warm surfaces to cooler surfaces, this process continues until both surfaces attain the same temperature. It involves the use of a metallic plate that has an air space above it, the air is then cooled by the long wave radiation under the radiator and the air cools down the building.

Passive cooling creates a system with maximum efficiency, the application of the above discussed techniques will reduce energy demand and increase thermal comfort. These techniques require minimum or no mechanical energy requirements for cooling the buildings. In the specific context of this paper, it is also required that the carbon footprint of the building be minimized. The building user behavior is very predictable to some extent and can be controlled and amended by the building designer to fit in these techniques. Passive cooling in this case should be based on a flexible boundary to able to achieve any practically meaningful result.

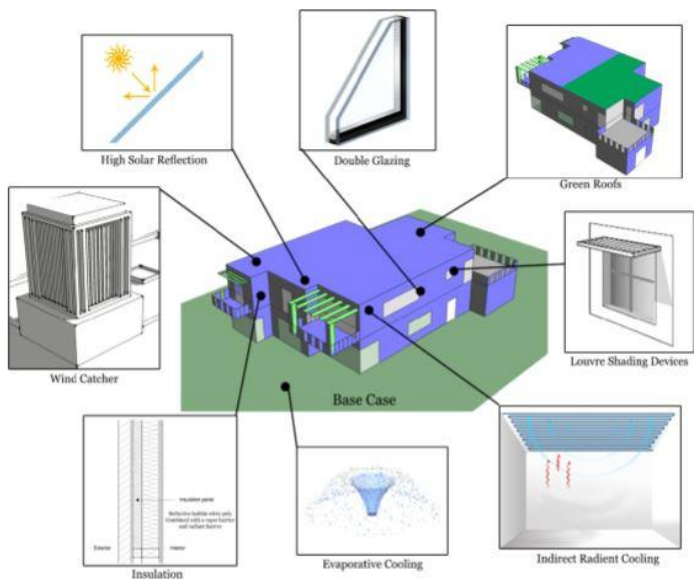

Figure 11: Sche matic of the adopted passive cooling design strategies. Source: [11].

\section{CONCLUSION}

This paper concludes that to achieve a passively cooled building, the climatic condition of the area must be taken advantage of. Solar heat gain must however be prevented as much as possible. It is a known fact that a passive building is the fundamental element of a cost effective and low energy demanding building. And this is because most of the energy demand goes to the mechanical cooling systems. This energy demand will tremendously reduce by the adoption of these strategies. These are: by properly analyzing the climatic, good building orientation, insulation of the building envelope, use of glazing that improve indoor thermal quality, the use of shading devices, vegetation for evaporative cooling and the use of radiative cooling elements. 


\section{REFERENCES}

[1]. H, Nyuk \& C, Yu, Tropical Urban Heat Islands: Climate Buildings and Greenery. (London: Taylor \& Franc is Group, 2009).

[2]. O.O Jegede The dynamics and thermodynamics of the atmosphere over West Africa, (Ile Ife, Nigeria, 1990).

[3]. O. K. Akande. Passive design strategies for residential buildings in a hot dry climate in Nigeria, (Bauchi 2010).

[4]. O. O. Ogunsote. An introduction to building climatology. A basic course for Architecture students, (Ahmadu Bello University, Zaria, 1991).

[5]. H. M. Mohd, Z. Xudong and Y. Hiroshi. Preliminary study of passive cooling strategy using a combination of PCM and Copper foam to increase thermal heat storage in building Facades (2010).

[6]. N. B. Geetha and R. Velraj Passive cooling methods for energy efficient buildings with and without thermal energy storage. (India, 2012)

[7]. O. O. Ogunsote. And P. Ogunsote. Optimizing Passive cooling systems in residential buildings, (University of Jos Nigeria 2003)

[8]. T. M. Boake The basic principles of passive design, (University of Waterloo, 2011).

[9]. Fislisbach and Zollikon Climate responsive building, Appropriate building construction in tropical and subtropical regions (SKAT 1993) P 324.

[10]. M. Burnett, Passive radiative cooling, (Stanford University 2015).

[11]. M. T. Hanan, Use of passive cooling strategies to improve thermal performance and reduce energy consumption in the UAE. (Faculty of engineering, British university of Dubai, 2014) 